\title{
Study on the Phase Transformation Kinetics of Sol-Gel Drived $\mathrm{TiO}_{2}$ Nanoparticles
}

\author{
H. Mehranpour, ${ }^{1}$ M. Askari, ${ }^{1}$ M. Sasani Ghamsari, ${ }^{2}$ and H. Farzalibeik ${ }^{1}$ \\ ${ }^{1}$ Department of Material Science and Engineering, Sharif University of Technology, Tehran 11155-9466, Iran \\ ${ }^{2}$ Solid State Lasers Research Group, Laser \& Optics Research School, NSTRI, Tehran 11365-8486, Iran
}

Correspondence should be addressed to M. Askari, askari@sharif.edu

Received 11 December 2009; Accepted 13 August 2010

Academic Editor: Jun Liu

Copyright (C) $2010 \mathrm{H}$. Mehranpour et al. This is an open access article distributed under the Creative Commons Attribution License, which permits unrestricted use, distribution, and reproduction in any medium, provided the original work is properly cited.

\begin{abstract}
Titanium dioxide nanopowders were synthesized by the diffusion controlled sol-gel process (LaMer model) and characterized by DTA-TG, XRD, and SEM. The prepared $\mathrm{TiO}_{2}$ nanoparticles have uniform size and morphology, and the phase transformation kinetics of obtained material was studied by interpretation of the X-ray diffraction patterns peaks on the base of Avrami equation. The stating point of anatase-rutile phase transformation temperature in the prepared nanoparticles was found between 100 and $200^{\circ} \mathrm{C}$. A decreasing trend on the intensity of X-ray peaks of anatase phase was observed up to $600^{\circ} \mathrm{C}$ when the presence of the rutile phase became predominant. Results indicated that the transition kinetics of the diffusion controlled prepared nanoparticles was begun at low temperature, and it can be concluded that the nucleation and growth sites in these particles were more than other. However, it has been found that the nucleation activation energy of rutile phase was $20 \mathrm{kj} / \mathrm{mol}$, and it is the lowest reported activation energy.
\end{abstract}

\section{Introduction}

Titania $\left(\mathrm{TiO}_{2}\right)$ continues to attract much interest, because of its wide variety of applications such as optical devices, sensors, and catalysis or photocatalysis $[1,2]$. There are several key factors in determining the properties of the final materials and their applications. For example, anatase shows advantages in applications such as photocatalytic material or dye-sensitized solar cells, and the particle size, shape and the morphology of $\mathrm{TiO}_{2}$ nanomaterial have an important role in the performance of prepared material [3-5]. On the other hand, rutile phase exhibits a higher refractive index and hiding power, as well as good chemical stability, and is becoming a candidate material for high-temperature separation and catalysis applications [6, 7]. Recently, it has been found that a mixture of anatase and rutile demonstrates better hot catalysis activity than does the single $\mathrm{TiO}_{2}$ phase $[8,9]$. As a sequence, studying the kinetics of the phase transformation of $\mathrm{TiO}_{2}$ nanomaterial is fundamentally important to control its properties and seems to be essential for special applications. During last decade, phase transformation of titanium oxide nanoparticles was a subject of scientific efforts and it has been proved that the intrinsic parameters such as particle size $[10,11]$, purity [12], powder compaction [13], aging [14], as well as peptization [15] can affect the temperature and the energy of phase transition of $\mathrm{TiO}_{2}$ nanoparticles. Banfield et al. $[16,17]$ purposed that a critical size may also be important and concluded that anatase is thermodynamically stable and the phase transformation will not begin with heating until the critical size is reached. It means that the nucleation and the growth have critical roles on the phase transformation of $\mathrm{TiO}_{2}$ nanoparticles. In solgel process, the formation of nanoparticles is explained on the base of two important theories that are called LaMer and Turkevich. The most famous and widely cited example of nucleation theory for cluster formation is the pioneer work of LaMer and Dinegar in 1950s [18]. LaMer theory is based on the diffusion controlled nucleation and growth of the same-size particles. By contrast, in the second theory (Turkevich theory) the nucleation and the growth of particle are controlled by chemical reaction of reactants in the gel [19]. In this paper, a diffusion controlled sol-gel process 
has been employed to obtain $\mathrm{TiO}_{2}$ nanoparticles with the uniform size and morphology and the phase transformation kinetics of synthesized material was studied by interpretation of the X-ray diffraction patterns peaks on the base of Avrami equation.

\section{Experimental}

In this investigation, the raw materials contain Titanium isopropoxide (TTIP) (98\%), Triethanolamine (TIPO), Ethanol, $\mathrm{HNO}_{3}$ (98\%) which have been purchased from Merck. The established controlled conditions for the preparation of $\mathrm{TiO}_{2}$ nanoparticles were as follows. First, a stock solution of $\mathrm{Ti}^{4+}$ was prepared by mixing titanium isopropoxide (TIPO: $\mathrm{Ti}\left[\mathrm{OCH}\left(\mathrm{CH}_{3}\right)_{2}\right]_{4}$ ) with triethanolamine (TEOA : $\left.\mathrm{N}\left(\mathrm{CH}_{2} \mathrm{CH}_{2} \mathrm{OH}\right)_{3}\right)$ at a molar ratio of TIPO : $\mathrm{TEOA}=1: 2$ under dry air to form a stable $\mathrm{Ti}^{4+}$ compound against the hydrolysis reaction at room temperature. The process followed by addition of doubly distilled water to make an aqueous stock solution that the concentration of $\mathrm{Ti}^{4+}$ is near to $5 \times 10^{-4} \mathrm{~mol} \cdot \mathrm{l}^{-1}$. Then, $10 \mathrm{~mL}$ of the stock solution was mixed with the same volume of doubly distilled water. In order to have $\mathrm{TiO}_{2}$ nanoparticles with uniform size and morphology alkaline regime has been selected and $\mathrm{pH}(\sim 9.6)$ was controlled by addition of $\mathrm{HClO}_{4}$ or $\mathrm{NaOH}$ solution. The final solution was placed in a screw-capped Pyrex bottle and aged at $100^{\circ} \mathrm{C}$ for 36 hours. Finally, the resulting highly viscous gel was mixed with $80 \mathrm{~mL}\left(2 \times 10^{-3}\right.$ molar) nitric acid and stirred at $25^{\circ} \mathrm{C}$ for 3 hours to dissolve the gel. The solution was set in pool water at $70^{\circ} \mathrm{C}$. After 4 minutes a sample has been taken from prepared solution, and $\mathrm{TiO}_{2}$ particles were separated from the resulting $\mathrm{Ti}^{4+}$ suspension by centrifugation. This work has been repeated several times and every time the concentration of the $\mathrm{Ti}^{4+}$ was measured by the atomic adsorption. The products were washed with distilled water and observed using a JEM1200EX II transmission electron microscope (SEM) with an acceleration voltage of $80 \mathrm{kV}$. For the identification of the products, X-ray diffractometry (XRD) was conducted using a Rigaku RAD-B system with a $\mathrm{CuK} \alpha$ beam.

\section{Results and Discussion}

As has been mentioned, the diffusion controlled of nucleation and growth process has been selected to prepare $\mathrm{TiO}_{2}$ nanoparticles with uniform size and shape. Therefore, the nanoparticles must be formed on the base of LaMer theory that is not very simple. Figure 1 shows the scanning electron microscopy (SEM) image of the $\mathrm{TiO}_{2}$ nanostructured material. The average particle size of $\mathrm{TiO}_{2}$ nanostructured material was near to $50 \mathrm{~nm}$. These particles were took out after centrifugation of solution. Figure 2 shows the TGA curve of $\mathrm{TiO}_{2}$ nanopowder. This curve essentially shows that the complete weight loss is due to removal of water occurred in $150^{\circ} \mathrm{C}$. Also, there are two exothermic peaks on the DTA curve which correspond to the decomposition of the probably existing organic species $\left(250^{\circ} \mathrm{C}\right)$ and the completed anatase-rutile phase transition $\left(500^{\circ} \mathrm{C}\right)$. In order

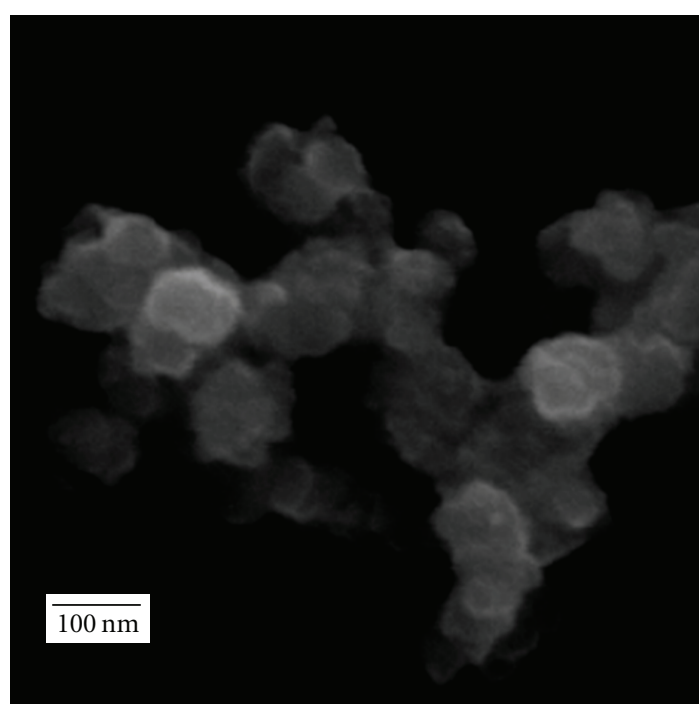

FIgURE 1: SEM micrographs of $\mathrm{TiO}_{2}$ particles after seeding.

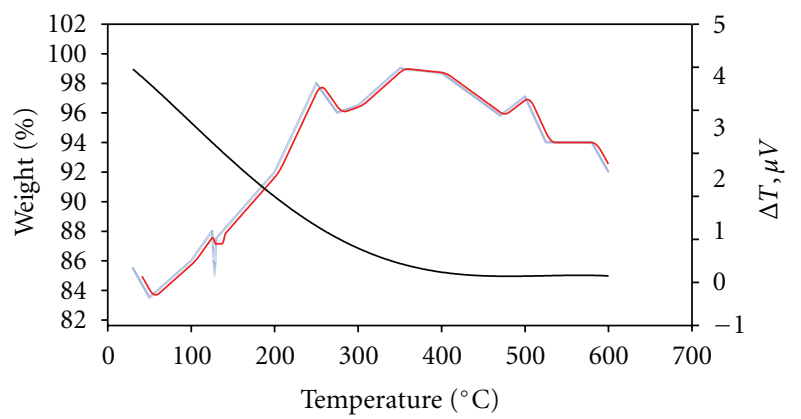

Figure 2: DTG analysis of prepared $\mathrm{TiO}_{2}$ nanoparticles.

to know the source of water and kind of organic species, we need to have a brief introduction about sol-gel process. As has been explained in our last paper [20], two chemical processes, which are called hydrolysis and polycondensation, are involved in the formation of the metal oxide (M-O-M) from the metal alkoxide precursor $\left(\mathrm{M}(\mathrm{OR})^{n}\right)$. The hydrolysis and polycondensation of metal alkoxide can be generally represented as the reaction of the alkoxide with $\mathrm{X}-\mathrm{OH}$ species as follows:

$$
\mathrm{M}(\mathrm{OR})_{n}+m \mathrm{XOH} \longrightarrow \mathrm{M}(\mathrm{OR})_{n-m}(\mathrm{OX})_{m}+m \mathrm{ROH} .
$$

where $\mathrm{R}$ is an alkyl group. (I) For $X=\mathrm{H}$, and $m=1$ it can be written as

$$
\mathrm{M}(\mathrm{OR})_{n}+\mathrm{H}_{2} \mathrm{O} \longrightarrow \mathrm{M}(\mathrm{OR})_{n-1} \mathrm{OH}+\mathrm{ROH} \text { (hydrolysis) }
$$

If we consider that $n=1$ and $X=\mathrm{M}$, it can be regarded as

$$
\mathrm{M}-\mathrm{OR}+\mathrm{HO}-\mathrm{M} \longrightarrow \mathrm{M}-\mathrm{O}-\mathrm{M}+\mathrm{ROH} \quad \text { (condensation). }
$$

The sol-gel process can be finally finished by

$$
\mathrm{M}-\mathrm{OH}+\mathrm{M}-\mathrm{OH} \longrightarrow \mathrm{M}-\mathrm{O}-\mathrm{M}+\mathrm{H}_{2} \mathrm{O} \text {. }
$$




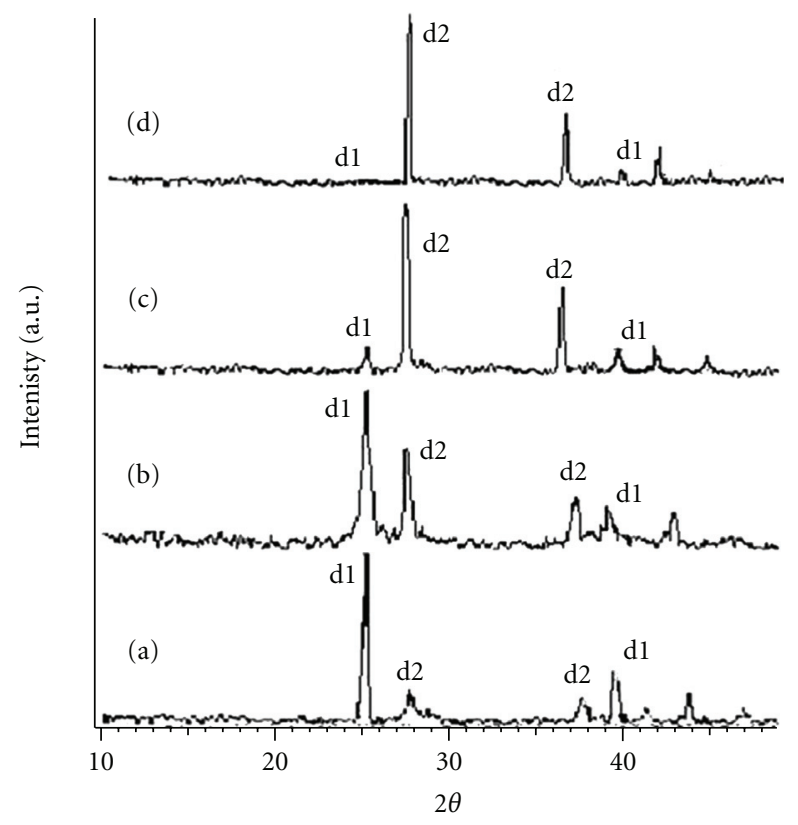

FIGURE 3: XRD patterns of samples reacted in the temperature range 200-800 ${ }^{\circ} \mathrm{C}$ for 2 hours (a) $200^{\circ} \mathrm{C}$, (b) $400^{\circ} \mathrm{C}$, (c) $600^{\circ} \mathrm{C}$, (d) $800^{\circ} \mathrm{C}$.

The sol-gel process resultant materials contain water, oxides and organic species. The absorption of water on the surface sites of oxide powder is physically, and organic species are absorbed chemically. Therefore, different temperatures need to desorb them from oxide surface. Figure 3 shows that the XRD patterns of 4 samples of $\mathrm{TiO}_{2}$ nanoparticles were thermally heated at $200,400,600$, and $800^{\circ} \mathrm{C}$ for 2 hours. In Figure 3 the pikes of $\mathrm{d} 1, \mathrm{~d} 2$ show anatase and rutile peaks, respectively. Also, there are not any corresponding peaks to confirm the crystallization of brookite in the temperature range of heat treatment. The obtained results indicated that the process is involved with the phase transformation of anatase to rutile in the starting material and the formation of rutile was begun from initial heat treatment process and the temperature, at which the anatase-rutile transformation becomes significant, is $200^{\circ} \mathrm{C}$. The phase content of a sample can be calculated from the integrated intensities of the abovementioned anatase, rutile, and brookite peaks. If a sample contains only anatase and rutile, the weight fraction of rutile $\left(X_{R}\right)$ can be calculated from

$$
X_{R}=\frac{1}{1+0.8\left(I_{A} / I_{B}\right)},
$$

where $X_{R}$ is the transformation fraction of rutile and $I_{A}$ represents the integrated intensity of the anatase (101) peak and $I_{R}$ the integrated intensity of rutile (110) peak. The intensity of the $2 \theta$ degree positions of 101 peak of the anatase phase and those of the 110 peak of rutile are given as a function of the treatment temperature. For the anatase reflection, a decrease of the Bragg (20) positions and the increase of the corresponding $d$ values in the Bragg reflection equation $(n \lambda=2 \times d \cdot \sin \theta)$ were observed up to $600^{\circ} \mathrm{C}$.

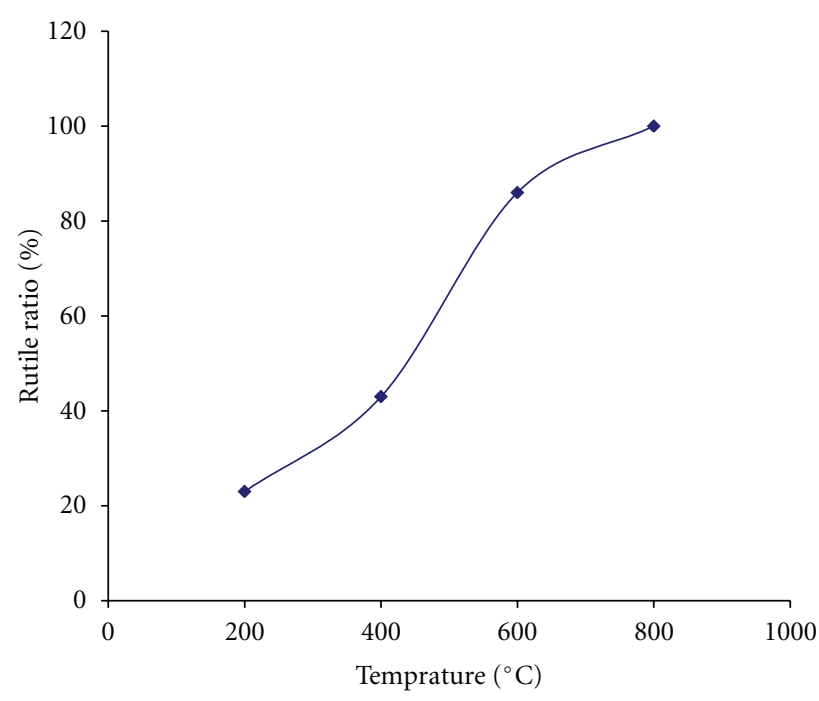

Figure 4: Evolution of the amount of Rutile phases in the various temperatures.

Since, the height of the rutile peak is longer enough than anatase peak, and so rutile phase is the dominant phase and becomes important from phase transformation point of view. Normally, the phase transformation of anatase to rutile is started at $500^{\circ} \mathrm{C}$. But, in heat-treated sample at $600^{\circ} \mathrm{C}$, the rutile is dominant phase and more than $80 \%$ of anatase is transformed to rutile. Figure 4 shows the phase contents of rutile in samples which were treated isochronally at 2 hours in the temperature range $200-800^{\circ} \mathrm{C}$. The percentage of rutile phase has been calculated by (5). The results indicate that the process involves the transformation of anatase in the starting material to rutile from its initial $23 \%$ at $200^{\circ} \mathrm{C}$ to $100 \%$ at $800^{\circ} \mathrm{C}$. High rapid reaction rate for this transformation shows that There must be lots of nucleation and growth site for transformation and also there is high driving force for the transition (free energy change for phase transformation). In summary, the main factor determining the rate for transformation of phase $a$ to phase $b$ by a nucleation and growth mechanism is $\Delta G_{a \rightarrow b}$, which is the difference in free energy between $a$ and $b$. So it seems that the free energy between rutile and anatase phase in this transformation is low. To clarify this inference the Avrami equation is used. It has been shown that kinetics of anatase-rutile phase transformation is followed by Avrami equation as follows:

$$
X=1-\exp (-k t)^{n},
$$

where $X$ is the fraction of transformation, $t$ is the time, $k$ is the kinetic constant, and $n=0.9 \sim 1.2$ for $\mathrm{TiO}_{2}$. The kinetic constant can be calculated for each transformation fraction. Activation energy for the transformation can be obtained using Arrhenius equation as given by

$$
\ln k=-\frac{E_{a}}{R T}+\ln k_{o}
$$

where $E_{a}$ is the activation energy, $k$ is the kinetic constant, $k_{0}$ is a material properties constant, $R$ is the universal gas 


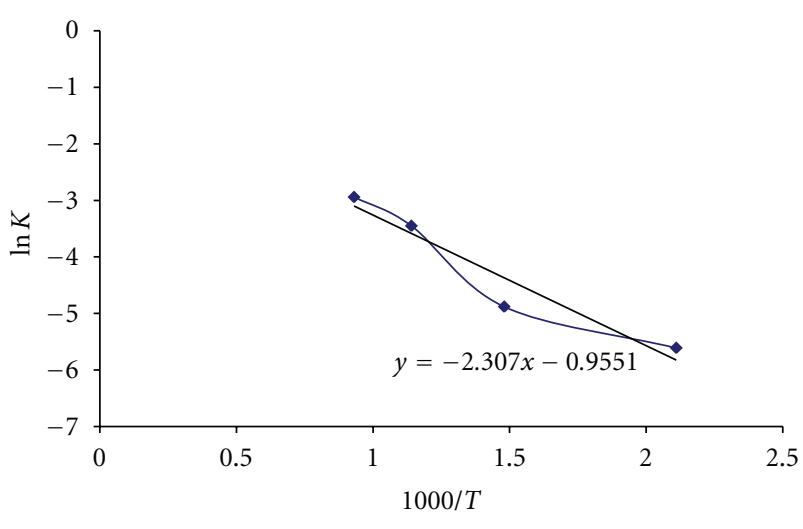

FIgURE 5: Arrhenius plot for samples aged at various times.

constant $(8.314 \mathrm{~J} / \mathrm{mol} \cdot \mathrm{K})$, and $\mathrm{T}$ is the absolute temperature. From the Arrhenius plot of various kinetic constants (Figure 5), and with calculation of slop, activation energy is obtained as $-20 \mathrm{kj} / \mathrm{mol}$. Numerous researchers, such as Kumar et al. [21, 22] and Zhang and Banfield [17], have investigated the kinetics of the anatase-to-rutile phase transformation, and the activation energy from their experiment was 147 and $248 \mathrm{kj} / \mathrm{mol}$, respectively. We believe that the high activation energy is due to nonuniformity of morphology and wide size distribution of the prepared $\mathrm{TiO}_{2}$ nanoparticles using sol-gel method. Therefore, the understanding of solgel-derived nanoparticles phase transition kinetics needs to have a uniform shape, morphology, and narrow size distribution. Also, the activation energy for the nuclei growth has been reported by Hsiang and Lin [15]. They showed that the activation energy depends on the experimental conditions and changes from 205 to $506 \mathrm{kj} / \mathrm{mol}$. Density functional theory [23] and tight binding [24] model have been employed to evaluate the routs of phase transformation mechanism in titanium oxide. According to these approaches, it has been found that the point defects have an important role in the phase transition of $\mathrm{TiO}_{2}$ material. On the other hand, the thermodynamically stable shape of $\mathrm{TiO}_{2}$ nanoparticles is very different from spherical and rod shapes of $\mathrm{TiO}_{2}$ nanomaterials [25]. It means that the spherical or rod shape of titanium oxide nanoparticles has different surface state density (point defects or surface dandling band) with respect to thermodynamically stable shape of $\mathrm{TiO}_{2}$ nanoparticles, and the density of surface state in these synthesized materials will be high. As has been argued in our last paper [26], the phase transformation of anatase to rutile depends to surface state. Therefore, the lowering of calculated activation energy of nucleation for samples prepared by this experiments is due to high surface state density and the uniformity of size and shape of resultant material that were caused from diffusion controlled synthesis process.

\section{Conclusion}

Prior treatment of synthesized titanium oxide nanopowders has remarkable effects on their properties as well as on the structural transitions observed under heating. At the present work, we have prepared $50 \mathrm{~nm} \mathrm{TiO}_{2}$ nanoparticles by sol-gel method based on LaMer theory. The particles were treated in different temperatures. The XRD pattern of particles indicated that the rutile phase transition phase was begun at lower than $200^{\circ} \mathrm{C}$. In comparison with other synthesized $\mathrm{TiO}_{2}$ nanoparticles the kinetics of phase transformation of our sample is very fast and so proposes that the activation energy of nucleation and growth is more than other prepared nanoparticles. It is concluded that the lowering of activation energy is due to diffusion controlled synthesis process and the uniformity of size and shape of resultant material.

\section{References}

[1] O. Harizanov and A. Harizanova, "Development and investigation of sol-gel solutions for the formation of $\mathrm{TiO}_{2}$ coatings," Solar Energy Materials and Solar Cells, vol. 63, no. 2, pp. 185195, 2000.

[2] B. Li, X. Wang, M. Yan, and L. Li, "Preparation and characterization of nano- $\mathrm{TiO}_{2}$ powder," Materials Chemistry and Physics, vol. 78, no. 1, pp. 184-188, 2002.

[3] M. A. Behnajady, N. Modirshahla, M. Shokri, H. Elham, and A. Zeininezhad, "The effect of particle size and crystal structure of titanium dioxide nanoparticles on the photocatalytic properties," Journal of Environmental Science and Health A, vol. 43, no. 5, pp. 460-467, 2008.

[4] K.-M. Lee, V. Suryanarayanan, and K.-C. Ho, "Influences of different $\mathrm{TiO}_{2}$ morphologies and solvents on the photovoltaic performance of dye-sensitized solar cells," Journal of Power Sources, vol. 188, no. 2, pp. 635-641, 2009.

[5] M. Ni, M. K. H. Leung, D. Y. C. Leung, and K. Sumathy, "An analytical study of the porosity effect on dye-sensitized solar cell performance," Solar Energy Materials and Solar Cells, vol. 90, no. 9, pp. 1331-1344, 2006.

[6] K.-N. P. Kumar, K. Keizer, and A. J. Burggraaf, "Stabilization of the porous texture of nanostructured titania by avoiding a phase transformation," Journal of Materials Science Letters, vol. 13, no. 1, pp. 59-61, 1994.

[7] Y. Li, J. Liu, and Z. Jia, "Morphological control and photodegradation behavior of rutile $\mathrm{TiO}_{2}$ prepared by a lowtemperature process," Materials Letters, vol. 60, no. 13-14, pp. 1753-1757, 2006.

[8] Z. Ambrus, K. Mogyorósi, A. Szalai et al., "Low temperature synthesis, characterization and substrate-dependent photocatalytic activity of nanocrystalline $\mathrm{TiO}_{2}$ with tailor-made rutile to anatase ratio," Applied Catalysis A, vol. 340, no. 2, pp. 153$161,2008$.

[9] S. Kim and S. H. Ehrman, "Photocatalytic activity of a surfacemodified anatase and rutile titania nanoparticle mixture," Journal of Colloid and Interface Science, vol. 338, no. 1, pp. 304$307,2009$.

[10] C.-S. Kim, I.-M. Kwon, B. K. Moon et al., "Synthesis and particle size effect on the phase transformation of nanocrystalline $\mathrm{TiO}_{2}$," Materials Science and Engineering C, vol. 27, no. 5-8, pp. 1343-1346, 2007.

[11] K.-R. Zhu, M.-S. Zhang, J.-M. Hong, and Z. Yin, "Size effect on phase transition sequence of $\mathrm{TiO}_{2}$ nanocrystal," Materials Science and Engineering A, vol. 403, no. 1-2, pp. 87-93, 2005.

[12] D. J. Reidy, J. D. Holmes, and M. A. Morris, "The critical size mechanism for the anatase to rutile transformation in $\mathrm{TiO}_{2}$ and doped- $\mathrm{TiO}_{2}$," Journal of the European Ceramic Society, vol. 26, no. 9, pp. 1527-1534, 2006. 
[13] J. Li, Y. Ye, L. Shen, J. Chen, and H. Zhou, "Densification and grain growth during pressureless sintering of $\mathrm{TiO}_{2}$ nanoceramics," Materials Science and Engineering A, vol. 390, no. 1-2, pp. 265-270, 2005.

[14] J. Yang, S. Mei, and J. M. F. Ferreira, "Hydrothermal synthesis of nanosized titania powders: influence of peptization and peptizing agents on the crystalline phases and phase transitions," Journal of the American Ceramic Society, vol. 83, no. 6, pp. 1361-1368, 2000.

[15] H.-I. Hsiang and S.-C. Lin, "Effects of aging on nanocrystalline anatase-to-rutile phase transformation kinetics," Ceramics International, vol. 34, no. 3, pp. 557-561, 2008.

[16] A. A. Gribb and J. F. Banfield, "Particle size effects on transformation kinetics and phase stability in nanocrystalline $\mathrm{TiO}_{2}$," American Mineralogist, vol. 82, no. 7-8, pp. 717-728, 1997.

[17] H. Zhang and J. F. Banfield, "New kinetic model for the nanocrystalline anatase-to-rutile transformation revealing rate dependence on number of particles," American Mineralogist, vol. 84, no. 4, pp. 528-535, 1999.

[18] V. K. LaMer and R. H. Dinegar, "Theory, production and mechanism of formation of monodispersed hydrosols," Journal of the American Chemical Society, vol. 72, no. 11, pp. 48474854, 1950.

[19] J. Turkevich, P. C. Stevenson, and J. Hillier, "A study of the nucleation and growth processes in the synthesis of colloidal gold," Discussions of the Faraday Society, vol. 11, pp. 55-75, 1951.

[20] S. Mahshid, M. Askari, and M. S. Ghamsari, "Synthesis of $\mathrm{TiO}_{2}$ nanoparticles by hydrolysis and peptization of titanium isopropoxide solution," Journal of Materials Processing Technology, vol. 189, no. 1-3, pp. 296-300, 2007.

[21] K.-N. P. Kumar, K. Keizer, and A. J. Burggraaf, “Textural evolution and phase transformation in titania membranes: part 1. Unsupported membranes," Journal of Materials Chemistry, vol. 3, no. 11, pp. 1141-1149, 1993.

[22] K.-N. P. Kumar, K. Keizer, A. J. Burggraaf, T. Okubo, and H. Nagamoto, "Textural evolution and phase transformation in titania membranes: part 2. Supported membranes," Journal of Materials Chemistry, vol. 3, no. 11, pp. 1151-1159, 1993.

[23] A. Barnard, Z. Saponjic, D. Tiede, T. Rajh, and L. Curtiss, "Multi-scale modeling of titanium dioxide: controlling shape with surface chemistry," Reviews on Advanced Materials Science, vol. 10, no. 1, pp. 21-27, 2005.

[24] D. R. Trinkle, M. D. Jones, R. G. Hennig, S. P. Rudin, R. C. Albers, and J. W. Wilkins, "Empirical tight-binding model for titanium phase transformations," Physical Review B, vol. 73, no. 9, Article ID 094123, 9 pages, 2006.

[25] A. S. Barnard, P. Zapol, and L. A. Curtiss, "Modelling the morphology and phase stability of $\mathrm{TiO}_{2}$ nanocrystals in water," Journal of Chemical Theory and Computation, vol. 1, pp. 107116, 2005.

[26] S. Mahshid, M. Askari, M. Sasani Ghamsari, N. Afshar, and S. Lahuti, "Mixed-phase $\mathrm{TiO}_{2}$ nanoparticles preparation using sol-gel method," Journal of Alloys and Compounds, vol. 478, no. 1-2, pp. 586-589, 2009. 

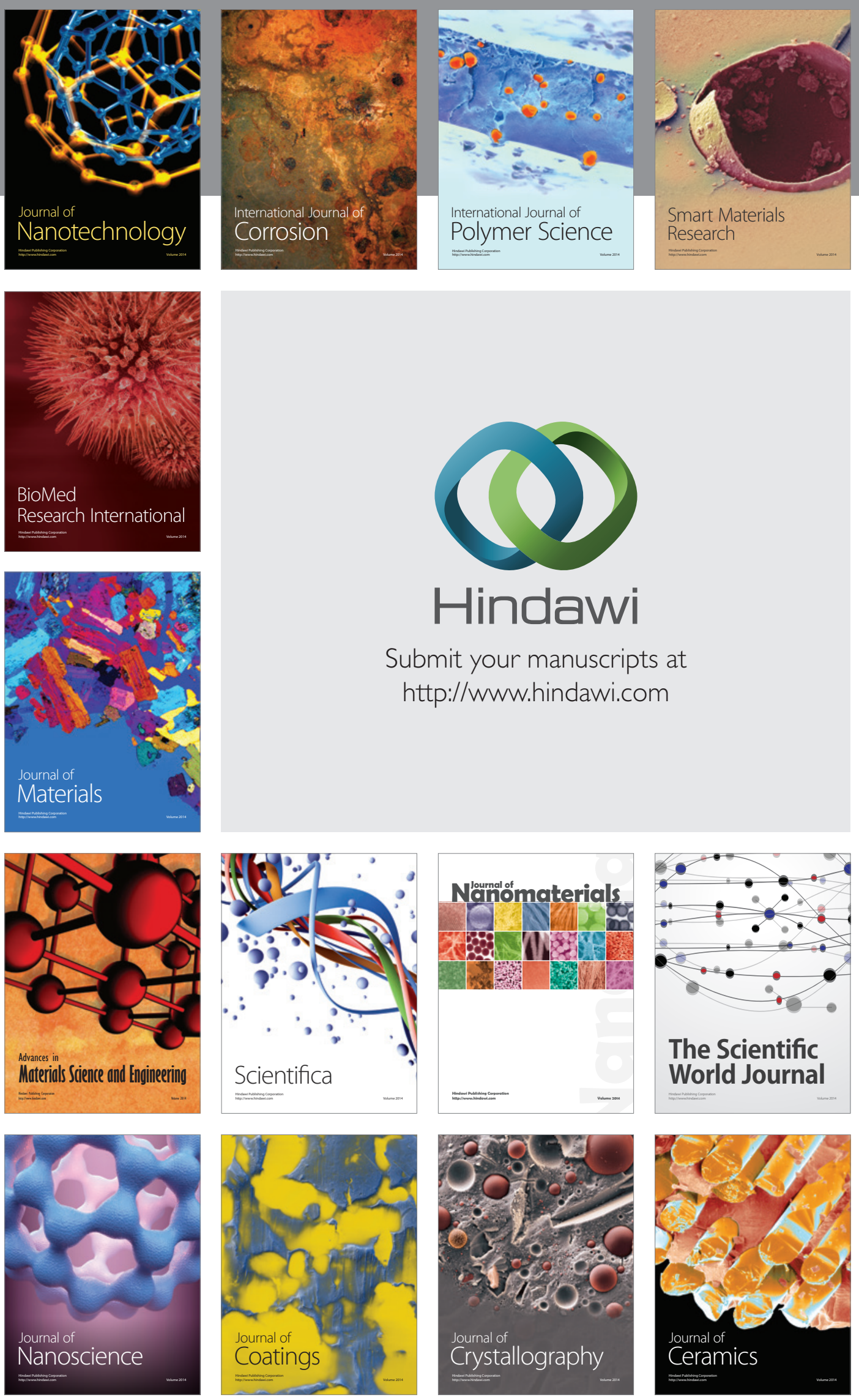

The Scientific World Journal

Submit your manuscripts at

http://www.hindawi.com

\section{World Journal}

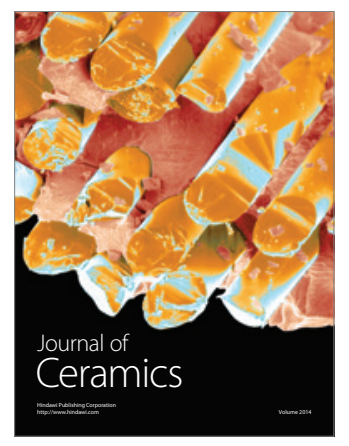

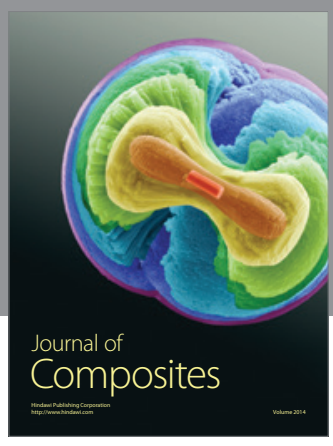
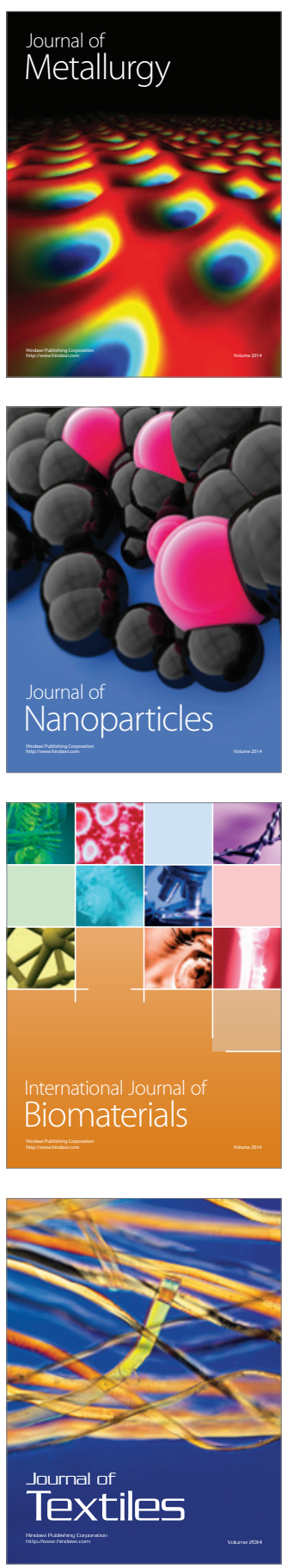